\title{
A MEMÓRIA E A PERCEPCÃO AMBIENTAL COMO INSTRUMENTOS DE EDUCAÇÃO AMBIENTAL: ESTUDO DE CASO DA LAGOA DAS CAPIVARAS - GAROPABA - SC
}

\author{
Amanda Bellettini Munari ${ }^{1}$ \\ Viviane Kraieski de Assunção ${ }^{2}$ \\ Carlyle Torres Bezerra de Menezes ${ }^{3}$
}

\section{INTRODUÇÃO}

A degradação dos ambientes costeiros, em função da ocupação urbana desordenada e ações antrópicas sem planejamento, tem acentuado o processo de destruição dos ecossistemas, que é agravado por sua capacidade restrita de suportar os impactos gerados por estas atividades.

A zona costeira brasileira possui uma importância estratégica, que pode ser evidenciada em vários aspectos, por abrigar um mosaico de ecossistemas de alta relevância ambiental que abriga enorme biodiversidade, marcada pela transição de ambientes terrestres e marinhos com interferências econômicas conflitantes e associadas a uma desordenada expansão urbana que acabam por fragilizar seu sistema (BRASIL, 2015).

Não é somente na zona costeira que se situam os problemas. Existe uma conexão direta e indireta tanto com o ambiente marinho quanto com a área continental, sendo que qualquer atividade desenvolvida no ambiente marinho interfere na ocupação dos espaços costeiros e continentais, pois é esta região de transição -zona costeira- que desempenha papel importante de ligação e trocas genéticas entre os ecossistemas terrestres e marinhos, classificado como ambiente complexo, diversificado e de extrema importância para sustentação da vida do mar (MARIANO, 2010).

O município de Garopaba (Santa Catarina, Brasil), assim como diversos municípios do litoral brasileiro, vem passando por um intenso processo de urbanização bem como destruição dos ecossistemas devido a grande procura da população para residir na zona costeira.

O turismo, por exemplo, é uma das atividades mais importantes das diversas cidades costeiras, principalmente as pequenas, que têm nele a principal

\footnotetext{
${ }^{1}$ Universidade do Extremo Sul Catarinense (UNESC) - abm@unesc.net

${ }^{2}$ Universidade do Extremo Sul Catarinense (UNESC) - vka@unesc.net

${ }^{3}$ Universidade do Extremo Sul Catarinense (UNESC) - cbm@unesc.net
} 
atividade econômica, inclusive com reflexos imobiliários negativos: a expansão dos loteamentos e a crescente demanda de áreas disponíveis favorecem o surgimento de construções irregulares, muitas vezes realizadas sem a devida autorização do Poder Público.

Devido a esta procura, o setor imobiliário pretendia a implantação de empreendimentos privados no município, o que acarretou em conflitos na região, por estes empreendimentos estarem diretamente situados na área que engloba a lagoa. Assim sendo, parte da Lagoa das Capivaras - a Lagoa Pequena - foi aterrada para a implantação de um loteamento, que mais tarde foi embargado devido a uma ação civil pública e hoje encontra-se abandonado.

A Lagoa das Capivaras, localizada na zona central do município, com uma área total de aproximadamente 20 hectares, além de sofrer com as consequências do aterramento da Lagoa Pequena, vem passando por um grave processo de degradação em virtude de estar situada em área urbanizada entre o mar e o continente, recebendo o despejamento de efluentes domésticos e industriais que está provocando a eutrofização da mesma, além de ter o aterramento de suas margens, assoreamento da bacia e supressão de sua mata ciliar (MARIANO, 2010).

É válido lembrar que as lagoas costeiras são responsáveis pela sobrevivência de muitas espécies aquáticas, como também para o desenvolvimento da fauna e flora que fazem parte de todo o ecossistema ali presente. Além disso, proporcionam a manutenção do lençol freático, contribuindo, também, para a estabilidade do clima no local, sendo fundamental à produtividade biológica, mantendo a biodiversidade inerente ao ambiente em estudo (NASCIMENTO, 2010; ASSIS, 2013).

Não há dúvida que grande parte dos problemas que enfrentamos está relacionada ao uso insustentável dos recursos em um sistema político, econômico, social e ecológico incoerente (MARRONI; ASMUS, 2005).

A educação ambiental surge como necessidade de reverter os caminhos que nossa cultura tomou (GADOTTI, 2000). A mesma tem um papel estratégico no processo de transição para uma sociedade sustentável, pois através dela se podem incorporar novos valores ambientas e paradigmas do conhecimento (LEFF, 2008).

Sachs (2002), enfatiza o potencial das populações locais agirem de maneira ambientalmente viável, utilizando estratégias que vise a sua reestruturação 
em bases ecologicamente sustentáveis aproveitando os conhecimentos locais e reabilitando áreas degradadas.

Diante desta realidade, este trabalho tem como foco a percepção e a memória ambiental dos moradores do município de Garopaba, de modo a investigar a forma como os sujeitos se relacionam com o meio e como compreendem os processos de mudança ou transformação ocorrido ao longo dos últimos anos.

\section{METODOLOGIA}

Primeiramente, foi realizada uma revisão bibliográfica sobre o assunto, a pesquisa possui uma perspectiva exploratória e está inserida no âmbito da abordagem qualitativa.

Na sequência, será realizada uma pesquisa de campo, com objetivo de conseguir informações e/ou conhecimentos acerca de um problema, para qual se procura uma resposta, ou de uma hipótese, que se queira comprovar, ou, ainda, descobrir novos fenômenos ou as relações entre eles (MARCONI; LAKATOS, 2010).

O método utilizado no trabalho é o estudo de caso, que segundo Goldenberg (2009), caracteriza-se por reunir um maior número de informações detalhadas, com a finalidade de apreender a totalidade de uma situação e descrever a complexidade de um caso concreto (p. 33).

O tempo de estadia no campo pode variar bastante, dependendo das pessoas pesquisadas, do seu grau de conhecimento e o relacionamento do pesquisador com o grupo e do tipo de problema abordado. O pesquisador precisa ganhar a confiança da comunidade, para poder obter as informações necessárias e que the interessam de forma consciente (ALBUQUERQUE; LUCENA; NETO, 2010).

O levantamento de dados ocorrerá predominantemente de forma direta, com o recolhimento de informações (MARCONI; LAKATOS, 2010; GIL, 1999), através da utilização de entrevistas semiestruturadas, as quais serão realizadas a partir de um roteiro predeterminado, onde serão gravadas e transcritas, permitindo ainda a utilização de outros temas e conteúdos esclarecidos no desenrolar da entrevista (CARVALHO, TOZONI-REIS, 2009).

Para a realização das entrevistas será utilizada a metodologia Bola de Neve, onde um sujeito que já possui uma convivência com o pesquisador indica 
outro sujeito para incluir na amostra. Esta metodologia é utilizada quando se trata de populações específicas e de um número pequeno de indivíduos (DEWES, 2013).

O trabalho de campo será realizado no Município de Garopaba, com os moradores. Para a realização das entrevistas, serão entrevistados 25 moradores ${ }^{4}$ com, no mínimo 18 anos, privilegiando os moradores que residem há mais de 10 anos no local (permanecendo o ano inteiro).

Vale destacar que a entrevista é uma técnica que o pesquisador se apresenta em frente ao público alvo e lhe faz questionamentos, com o objetivo de obtenção dos dados que the interessam para investigação, sendo também uma forma de interação com os indivíduos investigados (GIL, 1999).

A partir dos dados coletados e obtidos os resultados, serão interpretados, constituindo o núcleo central da pesquisa (MARCONI; LAKATOS, 2008).

Os dados coletados através das entrevistas serão transcritos e analisados de modo a classificar alguns trechos das entrevistas. Os trechos classificados, bem como comentários e observações, serviram de ponto chave para interpretar a percepção ambiental dos moradores sobre a situação anterior e atual da Lagoa.

\section{RESULTADOS E DISCUSSÃO}

A preocupação com a zona costeira é referente a contínua interferência das atividades humanas nos sistemas aquáticos continentais do Brasil produzindo impactos ambientais diretos e indiretos, com consequências para a qualidade da água, a biota e o funcionamento de lagoas, rios e represas.

No município de Garopaba, esta interferência é acentuada sobre a Lagoa das Capivaras, que por estar situada em região urbana recebe efluentes líquidos domésticos (esgoto), o que leva a uma eutrofização artificial da mesma, devido a grande carga de poluentes despejada. Ainda, suas margens estão sendo invadidas por habitações irregulares construídas ao longo dos anos, ocasionando enorme impacto a este ecossistema que configura-se como a união de uma vasta multiplicidade de espécies.

Assim sendo, a Lagoa das Capivaras vem passando por este processo de degradação, ato que gera grande preocupação tendo em vista que a Lagoa

\footnotetext{
${ }^{4}$ De acordo com Bauer e Gaskell (2008), o número ideal de entrevistas semiestruturadas em uma pesquisa qualitativa varia entre 15 e 25 , o que permite que um pesquisador realize a análise do material com profundidade.
} 
Pequena que era uma extensão da Lagoa das Capivaras foi aterrada devido à iniciativa da construção de um empreendimento privado, o qual não se consolidou e por condenação da justiça, uma multa deve ser paga, como medida remediadora do dano ambiental existente, bem como recuperação da Lagoa das Capivaras que sofre com o aterramento de sua extensão.

O aterramento de parte da Lagoa gerou diversos conflitos no município, onde se têm uma duplicidade de opiniões que ainda geram discussão sobre o assunto. Através de uma reunião com funcionários do órgão público municipal para discussão do projeto do Plano de Recuperação de Área Degradada (PRAD) para a Lagoa, estes relataram a inconformidade fundiária existente no terreno que encontra-se a lagoa e seu entorno, onde as escrituras estão irregulares e grande parte dos terrenos encontra-se em espera para desmembramento, ou seja, estes terrenos foram vendidos porém não se tem uma atualização das escrituras no órgão municipal, apenas com os diversos proprietários que dizem ser donos do espaço.

Este problema é resultado da falta de planejamento dos órgãos públicos, que por sua vez não tiveram os cuidados necessários com o recurso e atualmente a Lagoa das Capivaras vem sofrendo com esta problemática, reduzindo seu tempo de vida.

Conforme os níveis de matéria orgânica na água, a mesma pode ser classificada, como uma lagoa costeira de águas escuras, que, são caracterizadas por suas águas terem origem, principalmente, do lençol freático de áreas arenosas, rios cujas bacias de drenagem percorrem terrenos arenosos.

Assim sendo, a ocupação urbana desordenada na área próxima à lagoa tem causado séria degradação de seu ecossistema. O planejamento, bem como, o controle da entrada de efluentes domésticos lançados diretamente na Lagoa das Capivaras é uma das alternativas para recuperação e preservação da mesma, mas exige novas posturas na gestão de políticas.

Vale destacar que muitas pessoas utilizavam-se deste recurso para uso doméstico, criação de animais, cultivo, pesca, lazer e pela sua própria função natural como o controle de inundações, reservatório de água salobra e drenagem.

Com base nisto, na busca de alternativas para a reversão dos processos de degradação ambiental e encontra-se, em fase de elaboração, o projeto de um Plano de Recuperação de Área Degradada (PRAD), na perspectiva de trabalhar a 
educação ambiental com os moradores para a restauração da área e para uso de recreação e lazer da comunidade.

\section{CONCLUSÃO}

Conforme relatado anteriormente, a Lagoa das Capivaras sofre grande processo de degradação em relação ao saneamento, a ocupação desordenada e, a construção de grandes empreendimentos, que acarretou diversos conflitos socioambientais no município de Garopaba, bem como uma transformação de seu meio.

Esta transformação se deu através dos relacionamentos cotidianos dos indivíduos com o meio, por meio de conexões com os diversos grupos de convívio, os quais são fortalecidos ao longo do tempo, construindo lembranças, que com o passar do tempo ficaram guardadas em suas memórias.

Deste modo, a pesquisa sobre percepção e memória ambiental pode subsidiar um importante diagnóstico da situação de uma comunidade em relação ao meio, avaliando o nível de valoração dado aos diversos recursos naturais e serviços ecossistêmicos e dando suporte a programas de educação ambiental e ecodesenvolvimento (MARCZWSKI, 2006).

Assim, a investigação sobre a memória dos moradores, através de suas percepções sobre o meio ambiente - derivadas de seus relacionamentos com os diversos grupos de pessoas - pode ser utilizada como instrumento de educação ambiental de modo a sensibilizá-los e fazê-los perceber tais mudanças que foram brutais ao meio onde residem e utilizar deste contexto para estimular seu sentimento de pertença mostrando a importância da preservação e recuperação da Lagoa das Capivaras, desenvolvendo uma relação de maior cuidado e responsabilidade contribuindo para a mudança de conduta em relação ao meio ambiente.

Por fim, segundo Sachs (1986), explicitar os estilos de desenvolvimento ecologicamente prudentes e socialmente justos é, portanto, uma tarefa de primeiríssima importância na busca do ecodesenvolvimento: o cuidado com o futuro, em nome da solidariedade com as gerações vindouras.

\section{REFERÊNCIAS}

ALBUQERQUE, Ulysses Paulino de; LUCENA, Reinaldo Farias Paiva de; NETO, Ernani Machado de Freitas Lins. Seleção dos participantes da pesquisa. In: 
ALBUQUERQUE, Ulysses Paulino de; LUCENA, Reinaldo Farias Paiva de; CUNHA, Luiz Vital Fernandes Cruz da (Org.). Métodos e Técnicas na Pesquisa

Etnobiológica e Etnoecológica. Recife, PE: NUPPEA, 2010. p. 21-38.

BAUER, Martin; GASKELL, George. Pesquisa qualitativa com texto, imagem e som: um manual prático. 7. Ed. Petrópolis, RJ: Vozes, 2008.

BRASIL. Ministério do Meio Ambiente. Zona Costeira e seus usos múltiplos. 2015. Disponível em:< http://www.mma.gov.br/>. Acesso em: 22 jul. 2015.

CARVALHO, C. D.; TOZONI-REIS, M. F. C. Coletivizando saberes: (re) construção da memória ambiental de moradores da cidade de Botucatu. Artigo. Revistas em Educação Ambiental, vol. 4, n. 1 - p. 111-135, 2009.

DEWES, J. O. Amostragem em bola de neve e respondent-driven sampling : uma descrição dos métodos. Trabalho de Conclusão de Curso: Universidade Federal do Rio Grande do Sul. Porto Alegre, dez. 2013.

GADOTTI, M. Pedagogia da terra. 2ª Ed. São Paulo: Peirópolis, 2000.

GIL, Antonio Carlos. Métodos e técnicas de pesquisa social. 5. ed. São Paulo: Atlas, 1999.

GOLDENBERG, Mirian. A arte de pesquisar: como fazer pesquisa qualitativa em ciências sociais. 13.ed. Rio de Janeiro: Record, 2009.

LEFF, Enrique. Saber ambiental: sustentabilidad, racionalidad, complejidad, poder. Tradução de Lúcia Mathilde Endlich Orth. 6. ed. Petrópolis: Vozes, 2008. 494 p.

MARCONI, Marina de Andrade; LAKATOS, Eva Maria. Técnicas de pesquisa. In:_. Fundamentos de metodologia científica. 7. ed. São Paulo: Atlas, 2010

MARCZWSKI, M. Avaliação da Percepção ambiental em uma população de estudantes do ensino fundamental de uma escola municipal rural: um estudo de caso. Dissertação - Universidade Federal do Rio Grande do Sul, Programa de Pós Graduação em Ecologia. Porto Alegre, 2006.

MARIANO. N. M. DIAGNÓSTICO AMBIENTAL COMO SUBSÍDIO PARA RECUPERAÇÃO DE LAGOAS COSTEIRAS: ESTUDO DE CASO DA LAGOA DAS CAPIVARAS - GAROPABA - SC. Dissertação (Mestrado) - Universidade do Extremo Sul Catarinense, Programa de Pós-Graduação em Ciências Ambientais, Criciúma, 2010.

MARRONI, Etiene Villela; ASMUS, Milton L. Gerenciamento Costeiro: uma proposta para o fortalecimento comunitário na gestão ambiental. Pelotas: USEB, 2005. 149 p.

NASCIMENTO, A. P. ANÁLISE DOS IMPACTOS DAS ATIVIDADES ANTRÓPICAS EM LAGOAS COSTEIRAS - ESTUDO DE CASO DA LAGOA GRANDE EM 
PARACURU - CE. Dissertação. Programa de Pós-Graduação em Ciências Marinhas Tropicais. Fortaleza. 2010.

SACHS, I. Ecodesenvolvimento: crescer sem destruir. São Paulo: Véstice, 1986.

SACHS, I. Caminhos para o desenvolvimento sustentável. Rio de Janeiro:

Garamond, 2002. 